\title{
Purpureocillium lilacinum and Metarhizium marquandii as plant growth-promoting fungi
}

\author{
Noemi C Baron ${ }^{1}$, Andressa S Pollo ${ }^{2}$, Everlon C Rigobelo ${ }^{\text {Corresp. } 1}$ \\ ${ }^{1}$ Agricultural and Livestock Microbiology Graduation Program, São Paulo State University (UNESP), School of Agricultural and Veterinarian Sciences, \\ Jaboticabal, São Paulo, Brazil., Jaboticabal, Sao Paulo, Brazil \\ 2 Department of Preventive Veterinary Medicine and Animal Reproduction, São Paulo State University (UNESP), School of Agricultural and Veterinarian \\ Sciences, Jaboticabal, São Paulo, Brazil., University (UNESP), School of Agricultural and Veterinarian Sciences, Jaboticabal, São Paulo, Brazil., Jaboticabal, \\ Sao Paulo, Brazil \\ Corresponding Author: Everlon C Rigobelo \\ Email address: everlon.cid@unesp.br
}

Background. Specially on commodities crops, like soybean, maize, cotton, coffee and others, their high yields are reached mainly by the intensive use of pesticides and fertilizers. The biological management of crops is a relatively recent concept, and its application has increased expectations about a more sustainable agriculture. The use of fungi as plant bioinoculants has proven to be a useful alternative in this process, and research is deepening on genera and species with some already known potential. In this context, the present study focused on the analysis of the plant growth promotion potential of Purpureocillium lilacinum, Purpureocillium lavendulum and Metarhizium marquandii aiming its use as bioinoculants in maize, bean and soybean.

Methods. Purpureocillium spp. and M. marquandii strains were isolated from soil samples. They were screened for their ability to solubilize phosphorus (P) and produce indoleacetic acid (IAA) and the most promising strains were tested at greenhouse in maize, bean and soybean plants. Growth promotion parameters including plant height, dry mass and contents of $\mathrm{P}$ and nitrogen $(\mathrm{N})$ in the plants and in the rhizospheric soil were assessed.

Results. Thirty strains were recovered and characterized as Purpureocillium lilacinum (25), Purpureocillium lavendulum (4) and Metarhizium marquandii (1). From the trial for P solubilization and IAA production, seven strains were selected and inoculated in maize, bean and soybean plants. These strains were able to modify in a different way the evaluated parameters involving plant growth in each crop, and some strains distinctly increased the availability of $\mathrm{P}$ and $\mathrm{N}$, for the last, an uncommon occurrence involving these fungi. Moreover, the expected changes identified at the in vitro analysis were not necessarily found in planta. In addition, this study is the first to evaluate the effect of the isolated inoculation of these fungi on the growth promotion of maize, bean and soybean plants. 
1

4

5

6

7

8

9

10

11

12

13

14

15

16

17

18

19

20

21

22

23

24

25

26

27

28

29

30

31

32

33

34

35

36

37

40

41

42

43

44

45

\section{Purpureocillium lilacinum and Metarhizium marquandii as plant growth-promoting fungi}

Noemi Carla Baron ${ }^{1}$, Andressa de Souza Pollo ${ }^{2}$, Everlon Cid Rigobelo

${ }^{1}$ Agricultural and Livestock Microbiology Graduation Program, São Paulo State University (UNESP), School of Agricultural and Veterinarian Sciences, Jaboticabal, São Paulo, Brazil.

2 Department of Preventive Veterinary Medicine and Animal Reproduction, São Paulo State University (UNESP), School of Agricultural and Veterinarian Sciences, Jaboticabal, São Paulo, Brazil.

Corresponding Author:

Everlon Cid Rigobelo ${ }^{1}$

Access way Prof. Paulo Donato Castellane, Jaboticabal, São Paulo, 14884-900, Brazil

Email address: everlon.cid@unesp.br

\section{Abstract}

\section{Background}

High yields from crops, especially commodity crops such as soybean, maize, cotton, and coffee, are mainly achieved through the intensive use of pesticides and fertilizers. The biological management of crops is a relatively new concept, and its application has increased expectations for sustainable agriculture. The use of fungi as plant bioinoculants has proven to be a useful method of biological crop management, and research on genera and species with alreadyidentified potential is deepening. In this context, the current study analyzed the potential of Purpureocillium lilacinum, Purpureocillium lavendulum and Metarhizium marquandii for use as plant growth-promoting bioinoculants in maize, bean and soybean.

\section{Methods}

Purpureocillium spp. and M. marquandii strains were isolated from soil samples. They were screened for their ability to solubilize phosphorus (P) and produce indoleacetic acid (IAA), and the most promising strains were tested on maize, bean and soybean plants in a greenhouse. Growth promotion parameters, namely, plant height and dry mass and P and nitrogen (N) contents in the plants and the rhizospheric soil, were assessed.

\section{Results}

Thirty strains were recovered and characterized as Purpureocillium lilacinum (25), Purpureocillium lavendulum (4) and Metarhizium marquandii (1). From the P solubilization and IAA production trials, seven strains were selected and inoculated in maize, bean and soybean plants. These strains differently affected the evaluated parameters related to plant growth in each 
46

47

48

49

50

51

52

53

54

55

56

57

58

59

60

61

62

63

64

65

66

67

68

69

70

71

72

73

74

75

76

77

78

79

80

81

82

83

84

85

86

87

88

89

90

91

crop. Some strains distinctly increased the availability of $\mathrm{P}$ and $\mathrm{N}$; increased $\mathrm{N}$ availability is uncommon with these fungi. Moreover, the expected changes identified in the in vitro analysis were not necessarily found in planta. In addition, this study is the first to evaluate the effects of the isolated inoculation of these fungi on growth promotion in maize, bean and soybean plants.

\section{Introduction}

As it is in many other countries, agriculture is the main activity of the Brazilian economy. Brazil became the largest soybean producer worldwide in 2018 (Conab, 2019) and is the third largest producer of maize (Conab, 2016) and beans (Conab, 2017). Soybean and maize are the main grains exported, while beans are consumed within Brazil as a food source. Currently, due to awareness about the environmental and health risks from the excessive use of pesticides and fertilizers, agriculture is undergoing a transformation process, and alternatives for more sustainable management are being developed. In this context, microorganisms have gained increasing prominence due to the success of their current application and the promising results from innovative research in this field.

Associations with microorganisms favor the survival of plants in the environment for several reasons. Plant mutualistic fungi are currently recognized as a new and important source of bioactive compounds. They produce a significant number of secondary metabolites, including phytohormones (auxins, gibberellins, cytokinins, and abscisic acid) and antifungal and antibacterial compounds (Rai et al., 2014). Studies have shown that plants treated with a variety of symbiotic fungi are often healthier than untreated plants (Strobel, 2003; Hyde \& Soytong, 2008; Khan et al., 2008; Colla et al., 2015).

Such plant-fungus associations are established mainly by two groups of fungi, mycorrhizal and endophytic fungi (Bonfante \& Genre, 2010). Endophytic fungi are those capable of living endosymbiotically with plants without causing disease symptoms (Behie \& Bidochka, 2014a). They can act as plant growth promoters, increase the germination rate, improve seedling establishment, and increase plant resistance to biotic and abiotic stresses by producing antimicrobial compounds, phytohormones and other bioactive compounds. In addition, endophytic fungi are responsible for the acquisition of soil nutrients, including macronutrients such as phosphorus, nitrogen, potassium and magnesium, and micronutrients such as zinc, iron, and copper (Behie \& Bidochka, 2014a; Rai et al., 2014; Khan et al., 2015).

Among the several fungal species capable of endophytically colonizing plants, this study focuses on the application of Purpureocillium (formerly Paecilomyces) strains and Metarhizium marquandii (formerly Paecilomyces marquandii). Studies have shown that fungi of the genus Purpureocillium and other closely related fungi have attributes that promote plant growth; however, only a few studies have presented these results in planta.

Taxonomically, the genus Paecilomyces was introduced by Bainier (1907). It is a polyphyletic genus, with representatives in distinct families and even orders. In recent years, it has undergone extensive revision, which has resulted in several taxonomic changes. One of these was proposed by Luangsa-ard et al. (2011), who described an in-depth morphological and phylogenetic approach to Paecilomyces species. They proposed the genus Purpureocillium to accommodate the species Paecilomyces lilacinus, modifying it to Purpureocillium lilacinum, which is commonly found in soil and is one of the most studied nematophagous fungi (Baron, Rigobelo \& Zied, 2019). Some authors have already studied a large number of biological nematicides based on P. lilacinum strains (Atkins et al., 2005; Dong and Zhang, 2006; Baron, 
92 Rigobelo \& Zied, 2019). In many cases, these biological nematicides can replace chemical 93 nematicides, which are nonspecific and nonselective, do not affect the development of worm 94 eggs, are expensive, and are toxic to harmless species of invertebrates and vertebrates, including 95 humans (Li et al., 2015; Degenkolb \& Vilcinskas, 2016). is scarce information about this species, others from this genus, or any other formerly recognized as Paecilomyces in terms of plant growth promotion. Some studies have already described Paecilomyces/Pupureocillium species in plants as endophytes (Bills \& Polishook, 1991; Cao, You \& Zhou, 2002; Tian et al., 2004), indicating their ability to colonize plants. Thus, these fungi may be able to establish different interactions with plants to benefit themselves and their host. Therefore, this study aimed to isolate strains formerly recognized as Paecilomyces, mainly Purpureocillium strains, from soil; perform molecular characterization and in vitro tests to evaluate their abilities to solubilize $\mathrm{P}$ and produce IAA, which are characteristics related to growth promotion; and then select the best strains to be tested on maize (Zea mays), bean (Phaseolus vulgaris) and soybean (Glycine max) plants to assess their potential as biofertilizers.

\section{Materials \& Methods}

\section{Fungal isolation}

Fungal isolation was carried out from soil samples collected in an area of approximately $8.400 \mathrm{~m}^{2}(\sim 150 \times 56 \mathrm{~m})$ occupied by guava trees (Psidium guajava, Paluma variety, 173 individuals) and located in Taquaritinga town, São Paulo state, Brazil (GNSS: $21^{\circ} 22^{\prime} 20.9^{\prime \prime S}$; $48^{\circ} 35^{\prime} 24.6^{\prime \prime} \mathrm{W}$ Gr.). The guava trees in this area were highly infested with nematodes, which led to its use as a source of soil samples for Paecilomyces/Purpureocillium isolation. The area was divided into four similar quadrants. Five soil samples (up to $15 \mathrm{~cm}$ depth) were collected from each quadrant and mixed to obtain one composite sample for each quadrant.

In the laboratory, $10 \mathrm{~g}$ of each composite soil sample was taken and transferred to Erlenmeyer flasks containing $100 \mathrm{~mL}$ of sodium pyrophosphate solution $(1 \mathrm{~g} / \mathrm{L})$. The samples were homogenized on a rotary shaker for 60 minutes at $90 \mathrm{rpm}$ and then used for serial dilutions. One hundred microliter aliquots were plated on three different culture media: Martin's medium (Martin, 1950), DOC2 medium (Shimazu and Sato, 1996) and potato dextrose agar (PDA) supplemented with $1.5 \%$ sodium chloride $(\mathrm{NaCl})$ (adapted from Mitchell, Kannwischer-Mitchell \& Dickson, 1987). Martin's medium is a general medium for soil fungi, whereas PDA with $\mathrm{NaCl}$ and DOC2 are described as selective for Paecilomyces/Purpureocillium isolation. The plates were incubated at $25^{\circ} \mathrm{C}$ for up to 21 days and checked daily for the emergence of new colonies.

The isolated cultures were purified, and morphological confirmation to the genus level was performed by growth analysis on culture media and microscopic observations of slides prepared with lactophenol blue dye. The cultures were preserved in slants containing PDA at 4 ${ }^{\circ} \mathrm{C}$ and by ultrafreezing at $-80{ }^{\circ} \mathrm{C}$ with glycerol at $15 \%$ concentration.

\section{Molecular and phylogenetic analysis}

For DNA extraction, the fungi were grown in small flasks containing $40 \mathrm{~mL}$ of potato dextrose broth (PDB) for 3 to 4 days at $26-28{ }^{\circ} \mathrm{C}$. After incubation, the mycelium was recovered, washed with ultrapure water and oven dried at $50{ }^{\circ} \mathrm{C}$ for at least 12 hours. The dried mycelium was macerated with liquid nitrogen and used for DNA extraction according to Kuramae-Izioka 
137 (1997). Genomic DNA samples were purified with Wizard SV Gel and PCR Clean-up System

138

139

140

141

142

143

144

145

146

147

148

149

150

151

152

153

154

155

156

157

158

159

160

161

162

163

164

165

166

167

168

169

170

171

172

173

174

175

176

177

178

179

180

181

(Promega, São Paulo) according to the manufacturer's specifications.

DNA amplification was performed for the nuclear ribosomal DNA ITS1-5.8S-ITS2 (ITS

barcode) region with the primers ITS1 (5' TCCGTAGGTGAACCTGCGG 3') and ITS4 (5'

TCCTCCGCTTATTGATATGC 3') (White et al., 1990) and for a fragment of the coding region of the $\beta$-tubulin protein $(\beta T U B 2)$ with the primers $\mathrm{Bt} 2 \mathrm{a}\left(5^{\prime}\right.$

GGTAACCAAATCGGTGCTGCTTTC 3') and Bt2b (5'

ACCCTCAGTGTAGTGACCCTTGGC 3') (Glass \& Donaldson, 1995).

The reactions were performed with $1 \mathrm{X}$ buffer $(50 \mathrm{mM} \mathrm{KCl}, 200 \mathrm{mM}$ Tris-HCl, $\mathrm{pH} 8.4) ; 2$ $\mathrm{mM} \mathrm{MgCl} 2 ; 0.2 \mathrm{mM}$ dNTPs; 0.5 U Platinum Taq DNA polymerase (Invitrogen, California); 2.5 pmol of each primer; $0.001 \mathrm{mg}$ BSA; $0.1 \mu \mathrm{L}$ DMSO; $60 \mathrm{ng}$ of genomic DNA and sterile pure water to $20 \mu$ l. The amplification program was as follows: $95{ }^{\circ} \mathrm{C}$ for 4 minutes; followed by 35 cycles at $94^{\circ} \mathrm{C}$ for 50 seconds, primer annealing temperature $\left(55^{\circ} \mathrm{C}\right.$ for ITS1 and ITS4 and 58 ${ }^{\circ} \mathrm{C}$ for Bt2a and Bt2b) for 30 seconds, and $72{ }^{\circ} \mathrm{C}$ for 40 seconds; and a final extension at $72{ }^{\circ} \mathrm{C}$ for 10 minutes.

The PCR products were purified using the ExoSAP-IT PCR product cleanup kit (Applied Biosystems, California) following the manufacturer's instructions. The sequencing reaction was performed with a BigDye Terminator kit (Applied Biosystems, California) according to the manufacturer's instructions. Sequencing was performed by capillary electrophoresis on an ABI3130 sequencer.

The electropherograms were submitted to the PHRED/PHRAP/CONSED program package (Green, 1996; Ewing et al., 1998; Gordon, Abajian \& Green, 1998). Only nucleotides with a Phred quality equal to 20 or higher were considered. The edited sequences were compared to those deposited in the NCBI (National Center for Biotechnology Information) GenBank database using the BLAST tool (Altschul et al., 1990) and in the CBS database (Centraalbureau voor Schimmelcultures-Westerdijk, Netherlands).

For phylogenetic analysis, the sequences of the ITS and $\beta T U B 2$ regions of the 30 strains and other sequences collected were aligned separately using the MUSCLE tool (Edgar, 2004). The best evolutionary model was selected according to the Akaike information criterion (AIC) using the MODELTEST version 3.7 tool (Posada \& Crandall, 1998; Posada \& Buckley, 2004). The sequences of the two regions were processed separately and subsequently concatenated for Bayesian analysis using the Markov Chain-Monte Carlo algorithm (MCMC) with the software MRBAYES version 3.2.3 (Ronquist \& Huelsenbeck, 2003). The evolutionary model was used to analyze each region separately, and the concatenated sequences of the two genes corresponded to substitution type 6 and gamma distribution. The phylogram obtained was graphically edited with DENDROSCOPE version 3 software (Huson \& Scornavacca, 2012).

\section{Phosphorus solubilization and indoleacetic acid (IAA) production assays}

To verify the P solubilization ability of the fungi, Erlenmeyer flasks $(125 \mathrm{~mL})$ containing $50 \mathrm{~mL}$ P solubilization broth from Nahas, Fornasieri \& Assis (1994) were prepared using fluorapatite $(5 \mathrm{~g} / \mathrm{L})$ as the sole $\mathrm{P}$ source. To detect the IAA production ability, the 30 strains were grown in $125 \mathrm{~mL}$ Erlenmeyer flasks containing $50 \mathrm{~mL}$ of dextrose yeast glucose sucrose medium (DYGS) containing the amino acid tryptophan (Milani et al., 2019). In both tests, the flasks were inoculated with three disks of mycelium $(8 \mathrm{~mm}$ diameter) cultured for 7 days on PDA and then incubated for 7 days on a rotary shaker at $25^{\circ} \mathrm{C} \pm 1{ }^{\circ} \mathrm{C}$ and $100 \mathrm{rpm}$.

Peer) reviewing PDF | (2019:12:44083:1:2:NEW 13 Mar 2020) 
182

183

184

185

186

187

188

189

190

191

192

193

194

195

196

197

198

199

200

201

202

203

204

205

206

207

208

209

210

211

212

213

214

215

216

217

218

219

220

221

222

223

224

225

226

227
After incubation, the samples were vacuum-filtered using preweighed filter paper to separate the mycelial biomass. The amount of soluble $\mathrm{P}$ in the filtrate was determined by the Ames method (1966). For IAA detection, Salkowski reagent was added to the filtrate for the colorimetric reaction, and spectrophotometric readings were performed at $530 \mathrm{~nm}$. Absorbance values were used to quantify soluble $P$ and IAA production by comparison with standard curves with defined $\mathrm{P}$ and IAA concentrations. The filter papers with the biomass were oven-dried at 40 ${ }^{\circ} \mathrm{C}$ for 48 hours and weighed again to obtain the dry biomass values. The data are presented as micrograms of $\mathrm{P}$ solubilized per gram of dried mycelium $(\mu \mathrm{g} \mathrm{P} / \mathrm{g})$ and micrograms of IAA produced per gram of dried mycelium ( $\mu \mathrm{g}$ IAA/g).

\section{Mass production of selected strains}

The isolates selected in the screening tests (P solubilization and IAA production) were mass-grown on parboiled rice. The production process followed the Alves \& Pereira (1998) methodology. The rice was inoculated with suspensions containing $10^{6}$ conidia $/ \mathrm{mL}$ obtained by scraping cultured plates containing the selected strains grown on PDA for 7 days with $0.1 \%$ Tween 80 solution and standardized with a hematocytometer. The inoculation was performed by injecting approximately $5 \mathrm{~mL}$ of the suspensions into the rice with a needle and syringe. Rice colonization occurred at $25^{\circ} \mathrm{C}$ for 15 days, and then the rice was transferred to plastic trays for drying for 3 to 5 days. The dried rice was packed in plastic bags and stored in a freezer at $-20{ }^{\circ} \mathrm{C}$.

\section{Greenhouse experiments}

Selected strains were tested in maize (hybrid 2B587PW Dow Agro Sciences), bean (BRS FC402 Embrapa) and soybean (Intacta RR2 Pro Monsanto) plants under greenhouse conditions.

Five-liter pots were filled with unsterilized sifted ravine soil. A preliminary soil analysis was carried out, and nitrogen $(\mathrm{N})$, phosphorus $(\mathrm{P})$ and potassium $(\mathrm{K})$ correction fertilization was prepared for planting following the guidelines of Raij et al. (1997) for each crop. Urea, simple superphosphate and potassium chloride were used as sources of N, P and K, respectively. Each pot received 5 to 6 seeds. After germination, thinning was performed to maintain three plants per pot. A volume of approximately $250-300 \mathrm{~mL}$ of water was supplied once a day to each pot.

Inoculation was carried out with suspensions of each strain. The suspensions were prepared from the lavage of the colonized rice with $0.1 \%$ Tween 80 solution, and the concentrations were standardized with a hematocytometer to $10^{8}$ conidia/mL. Each pot received $20 \mathrm{~mL}$ of suspension. Two inoculations were performed in the soil: the first at sowing and the second 15 days after sowing. The viability of the conidia was evaluated at both inoculations by counting the number of conidia with germ tubes (\%) after 17 hours of incubation on PDA at 26 ${ }^{\circ} \mathrm{C}$.

After 30 days, the pots were disassembled, and the following parameters were evaluated: 1) plant height: measurements were taken from the apex to the base for soybean and bean plants and from the apex of the third leaf to the base for maize plants; 2) dry mass: the plants were split into shoots and roots, dried in a forced-ventilation oven for 72 to 96 hours at $65{ }^{\circ} \mathrm{C}$ and then weighed in a semianalytical balance; 3) $\mathrm{P}$ and $\mathrm{N}$ in the rhizospheric soil: a sample of rhizospheric soil was collected from each pot and used to evaluate the P content according to Raij et al. (2001). For the soybean plants only, the $\mathrm{N}$ content in the soil was determined according to Malavolta, Vitti \& Oliveira (1997); 4) P and N in shoot and roots: dried shoot and root samples were ground and used for the determination of $\mathrm{P}$ and $\mathrm{N}$ contents. The $\mathrm{P}$ content determination was performed by nitric-perchloric digestion followed by spectrophotometric analysis

Peer) reviewing PDF | (2019:12:44083:1:2:NEW 13 Mar 2020) 
228

229

230

231

232

233

234

235

236

237

238

239

240

241

242

243

244

245

246

247

248

249

250

251

252

253

254

255

256

257

258

259

260

261

262

263

264

265

266

267

268

269

270

271

272

273

(Malavolta, Vitti \& Oliveira, 1997), and the $\mathrm{N}$ content was determined by sulfur digestion followed by titration (Malavolta, Vitti \& Oliveira, 1997).

\section{Statistical analysis}

The in vitro tests of $\mathrm{P}$ solubilization and IAA production were performed in a completely randomized design for the 30 strains, and each strain was considered a treatment with three replicates. The $\mathrm{F}$ test was carried out for variance analysis, followed by Tukey's test at 5\% probability for comparison of the means.

The greenhouse experiment was carried out in a completely randomized design with four replicates ( 1 replicate $=1$ pot), with each pot containing 3 plants. Data were submitted to variance analysis followed by Duncan's test at 5\% probability for comparison of the means. 2015).

Statistical analysis was performed using AGROESTAT software (Barbosa \& Maldonado,

\section{Results}

\section{Fungal isolation and molecular characterization}

A total of 30 fungal strains morphologically recognized as Paecilomyces/Purpureocillium were obtained from the isolation. Of these 30 strains, two were obtained from Martin's medium, five from PDA supplemented with $\mathrm{NaCl}$, and the remaining 23 from the DOC2 medium. In this study, the strains are referred to with the prefix LSM followed by the numerical code associated with the isolate (e.g., LSM 6).

The phylogenetic trees were developed with the ITS, $\beta T U B 2$ and concatenated sequences of the 30 strains obtained from this study and sequences from published strains and strains deposited in culture collections, mainly those from type strains of each species and species belonging to closely related families. They are presented in Figs. 1, 2 and 3, respectively, and Table 1 lists all sequences used in the analysis with their respective GenBank accession numbers.

\section{In vitro screening tests and selection of strains for in planta tests}

The results for fluorapatite solubilization by the 30 strains are shown in Fig. 4. The strains LSM 24, 14 and 65 of P. lilacinum were the three most effective P solubilizers from fluorapatite, with LSM 24 solubilizing the highest amount of P.

For IAA production, impressive results were obtained and are presented in Fig. 5. The strain LSM 65 of $P$. lilacinum produced more IAA than the other strains by a significant margin, followed by LSM 62 (P. lilacinum), LSM 68 (M. marquandii), LSM 183 and LSM 179 ( $P$. lilacinum).

LSM 24, 14 and 65 were the best P solubilizers. Despite the primary statistical relevance of LSM 24, the two remaining strains were also selected because of their statistical relevance compared with the lowest P solubilizer strain in this test, LSM 73 (Fig. 4).

Regarding IAA production, strains LSM 65 and 62 were the best producers. However, using the same criterion applied in the P solubilization test, strains LSM 68, 179 and 183 were selected due to their statistical relevance compared with the lowest IAA producer, LSM 187.

Therefore, based on the screening tests, LSM 14, 24, 62, 65, 179 and 183 of P. lilacinum and LSM 68 of M. marquandii were selected for the in planta tests. 
274

275

276

277

278

279

280

281

282

283

284

285

286

287

288

289

290

291

292

293

294

295

296

297

298

299

300

301

302

303

304

305

306

307

308

309

310

311

312

313

314

315

316

317

318

\section{Greenhouse tests with the selected strains}

Fig. 6 summarizes the significant results obtained from the statistical analysis of the evaluated parameters for maize, bean and soybean plants. All statistical data related to the three crops tested can be found in supplemental Tables S1, S2 and S3.

In maize plants, the $P$. lilacinum strain LSM 65 provided a significant increase in plant height compared with that in the control (Fig. 6A). The P. lilacinum strain LSM 24 significantly increased $\mathrm{P}$ levels in the soil compared with those of the control $(66.7 \%)$ and the other strains (Fig. 6B).

The results observed in maize plants match the in vitro potential described for the tested fungi. LSM 65 was selected as the best IAA producer (Fig. 5) and was also a good P solubilizer, surpassed only by LSM 24 and 14 (Fig. 4). Although it did not stand out among the evaluated parameters involving $\mathrm{P}$ quantification, inoculation with this strain had a significant effect on the vegetative growth of the plant (shoot height), which was certainly related to IAA production. The best in vitro P solubilizer, LSM 24 (Fig. 4), showed high P solubilization under greenhouse conditions, which could be detected in the soil (Fig. 6B).

No significant differences were detected in $\mathrm{N}$ content in the shoot; however, in the roots, all the inoculated fungi were able to significantly increase the levels of N, except for LSM 14 (Fig. 6C). Notably, LSM 65 and 24 increased $\mathrm{N}$ levels in the roots by $39.2 \%$ and $38.0 \%$, respectively, compared with that of the control.

For bean plants, unlike in maize, no significant differences in plant height, dry mass, $\mathrm{N}$ contents or P levels in the soil and roots were found in the treatments that received fungal inoculation (Table S2); however, significantly higher P levels were found in the shoots of bean plants inoculated with LSM 68 (M. marquandii), LSM 179 (P. lilacinum) and LSM 183 ( $P$. lilacinum), presenting $79.2 \%, 75.5 \%$ and $94.3 \%$ more $P$ than in the control, respectively (Fig. 6D).

These data indicate the strong P solubilization ability of these strains, suggesting that the $\mathrm{P}$ was solubilized from the soil and that by direct absorption or by transportation through the hyphae, in the case of an endophytic interaction, the P reached the plants and was allocated to the shoot.

In soybean plants, LSM 179 promoted a significant increase in plant height compared to that of the control (Fig. 6E). For the variables related to dry mass, plants inoculated with LSM 24 had significantly higher root and total dry mass than those of the control (Fig. 6F - G).

In addition to increasing plant height, LSM 179 promoted a significant increase in $\mathrm{N}$ levels in the soil (Fig. $6 \mathrm{H}$ ), more than doubling the amount of $\mathrm{N}$ found in the control treatment. However, for the shoot and root, none of the strains led to a significant increase in $\mathrm{N}$ levels. The evaluation of the $\mathrm{P}$ content in the soil and in the plants revealed that none of the strains promoted a significant increase in $\mathrm{P}$ content.

Despite such positive results, some negative interactions were observed and should be mentioned. For maize plants, LSM 183 was responsible for significant decreases in plant height and shoot, root and total dry mass compared with the control. Additionally, LSM 179 led to a reduction in the height of bean plants.

\section{Discussion}

\section{Isolation and molecular characterization}


The use of selective media is common when the cultivation of a specific group is desired. In this study, two of the three media tested for fungal isolation were selective. Martin's medium (Martin, 1950) is generalist medium for soil fungi and was not demonstrated to be efficient for the recovery of the genus of interest. There are only a few media recommended in the literature for Purpureocillium (formerly Paecilomyces) isolation, and most of them include the addition of sodium chloride to PDA due to the characteristic osmotolerance of the genus. In this study, the recommendation of Mitchell, Kannwischer-Mitchell \& Dickson (1987) to use PDA with 1.5\% sodium chloride was adopted. However, the authors also suggested the use of PCNB (pentachloronitrobenzene) and benomyl in the medium. These are chemical fungicides that inhibit the growth of other highly sporulating fungi, especially Trichoderma, and thus favor the selective growth of Purpureocillium. As these chemicals are restricted by Brazilian law, they were not used, which is probably reflected in the recovery of only five strains of interest from this medium.

In the case of the DOC2 medium, Shimazu \& Sato (1996) described it as favorable for Beauveria bassiana isolation. However, Chen et al. (2010) isolated the new species

Paecilomyces echinosporus using DOC2 medium. It is a very poor medium, with high $\mathrm{pH}(\mathrm{pH}=$ 10) and high copper concentrations. Surprisingly, this medium presented the optimal selectivity for the target fungi, and the largest number of strains of interest (23) was obtained from it. Thus, in addition to being considered for the selective isolation of B. bassiana, DOC2 can also be used for the selective isolation of Purpureocillium from soil samples.

Regarding the molecular characterization of the strains, as shown in Fig. 1, it is possible to conclude from the ITS analysis that LSM 18, 42, 73 and 211 correspond to Purpureocillium lavendulum, LSM 68 is a strain of Metarhizium marquandii, and the remaining strains correspond to P. lilacinum. The same is shown in the phylogram of $\beta T U B 2$ (Fig. 2), except that there are no sequences of this gene for $P$. lavendulum, which makes the identification of LSM 18, 42, 73 and 211 implicit. However, despite the absence of $\beta T U B 2$ sequences for $P$. lavendulum, these four strains clustered outside of the $P$. lilacinum strains, as in the ITS analysis, indicating that it is a distinct and closely related species. The concatenated analysis of the ITS and $\beta T U B 2$ sequences (Fig. 3) confirmed the pattern observed for the analysis of the two separate genes, which confirms the reliability of the identifications.

Luangsa-ard et al. (2011) suggested the combination Purpureocillium lilacinum, which is in the family Ophiocordycipitaceae (Sung et al., 2007). Other important taxonomic changes had already occurred, such as the return of Paecilomyces javanicus and Paecilomyces farinosus to the genus Isaria as the new combinations Isaria javanica and Isaria farinosa, respectively (Luangsa-ard, Hywel-Jones \& Samson, 2004). Later, Kepler et al. (2017) suggested a new combination for these two species and for Paecilomyces fumosoroseus (=Isaria fumosorosea) within the genus Cordyceps, becoming C. javanica, C. farinosa and C. fumosorosea, respectively.

The species $P$. lavendulum was recently described (Perdomo et al., 2013) after a polyphasic analysis of the strains characterized as $P$. lilacinum. This species is closely related to $P$. lilacinum and is grouped in the same family, Ophiocordycipitaceae. Unlike $P$. lilacinum, $P$. lavendulum does not grow at $35^{\circ} \mathrm{C}$; it produces a yellowish pigment that diffuses in the culture medium, and its conidia are subglobous or lemoniform (Perdomo et al. 2013).

Until 2014, M. marquandii was recognized as Paecilomyces marquandii. Kepler et al. (2014) transferred the species to the genus Metarhizium because previous studies, such as 
364 Luangsa-ard et al. (2011), had previously indicated the genetic grouping of this species with

365

366

367

368

369

370

371

372

373

374

375

376

377

378

379

380

381

382

383

384

385

386

387

388

389

390

391

392

393

394

395

396

397

398

399

400

401

402

403

404

405

406

407

408

409 members of the family Clavicipitaceae, which includes the genus Metarhizium.

\section{Plant growth promotion by the fungi}

To assess the potential of these strains for plant growth promotion, their P solubilization and IAA production abilities were tested in vitro. Phosphorus is a limiting nutrient in the soil and is essential for plant development because it constitutes energy molecules, nucleic acids, and coenzymes, among other compounds of great importance at the cellular level (Patil et al., 2012; Gaind, 2016). Fluorapatite was chosen for this analysis because it is a naturally occurring rock phosphate that is abundant in Brazilian soils and in different regions of the world. In addition, it has been reported that many microorganisms are generally capable of solubilizing tricalcium phosphate, the most common insoluble P source used in in vitro tests. However, these microorganisms may not be able to solubilize other phosphates, such as fluorapatite. This occurs because tricalcium phosphate is an anamorphic mineral, while fluorapatite is a crystalline mineral derived from igneous rocks and, similarly to hydroxyapatite and chlorapatite, is much more resistant to microbial action (Fontaine et al., 2016).

Hernandez-Leal, Carrión \& Heredia (2011) described the ability of $P$. lilacinum to solubilize calcium phosphate, while Cavello et al. (2015) did not detect this ability in the $P$. lilacinum strain used in their study. To date, the ability to solubilize $\mathrm{P}$ from fluorapatite has not been reported in the literature for any of the species identified in this study. However, all 30 strains were able to use fluorapatite as a P source. LSM 24 of P. lilacinum was the best at this test and was able to solubilize more than $16 \mathrm{mg}$ of phosphate per gram of mycelium (Fig. 4).

The phytohormone IAA, the best-known auxin, is responsible for several effects on the development of shoots and roots, such as tropism responses, cell division, vascular tissue differentiation and the initiation of root formation (Jaroszuk-Scisel, Kurek \& Trytek, 2014). In addition to these benefits, IAA is a signaling molecule in many interactions between plants and microorganisms. For example, the synthesis of IAA in the rhizosphere can modify the root architecture, increasing not only the mass but also the root area; the increased root area is then colonized by microorganisms and simultaneously increases the acquisition of nutrients from the soil by the plant (Nieto-Jacobo et al., 2017). Cavello et al. (2015) were the first to report IAA production by $P$. lilacinum, describing a maximum production of $3.24 \mu \mathrm{g} / \mathrm{mL}$ of IAA under the conditions tested by the authors. The P. lilacinum strain LSM 65, which had the highest production of IAA among the 30 strains in this study, had an average production of $53.0 \mu \mathrm{g} / \mathrm{mL}$ of IAA, and the P. lilacinum strain LSM 179 had an average production of $19.5 \mu \mathrm{g} / \mathrm{mL}$ of IAA (Dataset S1).

P. lilacinum is a nematophagous and entomopathogenic species (Singh, Pandey \& Goswami, 2013; Goffré \& Folgarait, 2015) capable of the endophytic colonization of plant tissues (Bamisile et al. 2018). The same is reported for some species of Metarhizium, although no studies on this subject involving M. marquandii have been found in the literature.

Several studies have shown that the application of $P$. lilacinum under nematode infestation conditions, especially Meloidogyne spp. infestations, can improve the plant response to the presence of the pathogen and even promote plant growth. As an example, in their study, Nesha \& Siddiqui (2017) tested a strain of P. lilacinum and another of Aspergillus niger independently and together and assessed their growth promotion potential and ability to combat pathogens in carrots. The influences of fungal inoculation on plant height, dry and fresh mass, chlorophyll content in the leaves, number of galls in the roots, nematode population, and disease 
410 rates were evaluated, and the results showed that whether isolated together, the fungi were able

411 to positively affect the parameters related to growth promotion and negatively affect those

412 corresponding to the action of the pathogens.

413 However, only two studies have tested the effect of the inoculation of P. lilacinum on the 414 promotion of plant growth in the absence of pathogens. Lopez \& Sword (2015) evaluated the 415 effect of endophytic colonization by P. lilacinum and B. bassiana in cotton (Gossypium

416 hirsutum) and demonstrated that both fungi were able to increase the dry mass and the number of 417 flowers of the plants. Hernandez-Leal, Lopez-Lima \& Carrión (2016) also evaluated the effect of 418 P. lilacinum inoculation in oat plants in the absence of pathogens. In this study, the authors did 419 not obtain significant results for the growth promotion parameters evaluated, including fresh and dry mass and nutrient contents, with the tested strains of $P$. lilacinum.

Farias et al. (2018) tested the inoculation of $P$. lilacinum in combination with four fungi, B. bassiana, M. anisopliae, Pochonia chlamydosporia and Trichoderma asperellum, and obtained positive results in the evaluation of growth promotion parameters in soybean and maize plants; however, because they were tested together, it is difficult to determine which microorganism actually contributed to plant growth.

Seven strains were selected from the in vitro screening according to the established criteria and tested in maize, bean and soybean plants under greenhouse conditions. Therefore, this study is the first to demonstrate that $P$. lilacinum strains can significantly increase growth promotion parameters when inoculated in maize, bean and soybean plants without stimuli related to the presence of plant pathogens, such as nematodes. In this study, P. lilacinum strains LSM 65 and 179 , selected for their IAA production, were able to increase the height of maize and soybean plants, respectively (Fig. 6A and 6E). The P. lilacinum strain LSM 24, selected for its Psolubilization ability, promoted an increase in root and total dry mass in soybean plants (Fig. 6F). In the case of LSM 183 for maize and LSM 179 for bean plants (Tables S1 and S2), where their inoculation resulted in a decrease in plant height and biomass for the former and in plant height for the latter, it is possible to conclude that the fungi were not able to establish a positive interaction with the plants. The strains are not phytopathogens; however, when the conditions for interaction are provided, even if the expectation is for a positive relationship, the opposite can also occur. Specifically, in these cases, the strains and the plants probably competed for nutrients, and the use of energy in this competition was reflected in the decreases in the mentioned variables.

All the strains except LSM 14 were able to significantly increase the amount of $\mathrm{N}$ in maize roots, especially LSM 65 and 24. In combination with $\mathrm{K}, \mathrm{N}$ is the most essential nutrient for maize development (Coelho, 2006). Supplying $\mathrm{N}$ to a crop can be achieved by the application of chemical, mineral or biological fertilizers; the latter is achieved through the use of plant growth-promoting rhizobacteria (PGPR), which are able to fix atmospheric $\mathrm{N}$ to make it available to plants (Arzanesh et al., 2010; Abbasi et al., 2011).

For soybean and bean, which are leguminous plants, the $\mathrm{N}$ supply is associated with root nodulation with symbionts (e.g., Rhizobium). Once fixed, $\mathrm{N}$ is used as a raw material in the composition of organic molecules and is then mineralized again for the release of nitrogenous inorganic compounds that can be captured by plants (Behie \& Bidochka, 2014a).

However, biological $\mathrm{N}$ fertilization can also be achieved through mycorrhizal fungi (Miransari, 2011; Behie \& Bidochka 2014a), especially arbuscular mycorrhizae, which are able to supply essential nutrients such as $\mathrm{P}$ and $\mathrm{N}$ and receive carbon from photosynthesis in exchange (Bargaz et al., 2018; Bitterlich et al., 2018). McFarland et al. (2010) suggest that up to 
456

457

458

459

460

461

462

463

464

465

466

467

468

469

470

471

472

473

474

475

476

477

478

479

480

481

482

483

484

485

486

487

488

489

490

491

492

493

494

495

496

497

498

499

500

501

$50 \%$ of the required $\mathrm{N}$ supply can be obtained by mycorrhizal associations. Fungi obtain $\mathrm{N}$ from the soil efficiently through the release of $\mathrm{N}$ in inorganic forms from organic matter (Miransari et al., 2009). Atul-Nayyar et al. (2009) demonstrated that mycorrhizal fungi are capable of increasing the mineralization of organic matter in the soil, resulting in the release of large amounts of mineralized $\mathrm{N}$ that are readily available to be captured by plants.

The pioneering research of Behie et al. (2012) demonstrated that the ability to provide $\mathrm{N}$ to plants is not exclusive to mycorrhizal fungi. The authors reported the capacity for endophytic colonization in a strain of the entomopathogenic fungus Metarhizium robertsii and that the fungus was able to transfer $\mathrm{N}$ from infected and killed Galleria mellonella larvae to bean ( $P$. vulgaris) and grass (Panicum virgatum) plants. Since then, new studies such as Behie \& Bidochka (2014b) have been carried out evaluating the ability of endophytes to transfer N from insects in seven fungal species, $M$. robertsii, . guizhouense, M. brunneum, M. flavoviridae, $M$. acridum, B. bassiana and Akanthomyces (=Lecanicillium) lecanii, ad in four crops: two dicotyledons, G. max (soybean) and P. vulgaris (beans), and two monocotyledons, Triticum aestivum (wheat) and $P$. virgatum (grass). The authors highlighted that the five species of Metarhizium and B. bassiana were able to kill insect larvae, endophytically colonize the plants, and transfer $\mathrm{N}$ from the insects to the plants.

The increase in $\mathrm{N}$ levels in soil and plants (shoot or root) is not a common feature associated with the inoculation of nonmycorrhizal filamentous fungi in agricultural crops and has never been reported for $P$. lilacinum. Therefore, the results of this study strongly suggest that the tested strains, specifically LSM 65 and 24 in maize and LSM 179 in soybean, may have been able to accelerate organic matter becoming available in the soil in addition to establishing an endophytic relationship with the plants and participating in the transportation of $\mathrm{N}$ from the soil.

$\mathrm{P}$ solubilization from soil insoluble phosphates is spread widely across several groups of fungi and occurs through the production of organic acids or enzymes, i.e., phosphatases and phytases (Gaind, 2016). The most abundant phosphate form in the soil that can be readily absorbed by plants is orthophosphate $\left(\mathrm{PO}_{4}{ }^{3-}\right)$, which can also be absorbed by fungi. The transport of phosphates from fungi to plants is well characterized for arbuscular mycorrhizal fungi (Bargaz et al., 2018; Bitterlich et al., 2018). To date, little has been reported about the mechanism of P transportation from potentially endophytic fungi, such as $P$. lilacinum, to plants (Behie \& Bidochka 2014a). As previously mentioned, few studies describe the ability of $P$. lilacinum to solubilize $\mathrm{P}$, and even fewer studies describe the action of the fungus in planta in relationship to $\mathrm{P}$ availability.

The results obtained for LSM 24 in maize (Fig. 6B) confirmed its in vitro potential, showing that this strain is able to solubilize insoluble $\mathrm{P}$ from the soil and make it available to plants. However, the most impressive results were those obtained with the inoculation of LSM 68 (M. marquandii) and LSM 179 and LSM 183 (both P. lilacinum), selected for IAA production, which were able to greatly increase the $\mathrm{P}$ content in the shoots of bean plants (Fig. 6D), suggesting a possible endophytic interaction with positive responses to $P$ uptake.

It is interesting to analyze the differences in the ways that the strains interact with the different plant species. As previously observed, the results for maize plants corresponded with the data obtained from in vitro analysis, in which LSM 65 and 24 presented the best results for IAA production (Fig. 5) and P solubilization (Fig. 4), respectively, in addition to the increase in N, which did not occur in the bean crop. For the bean crop, LSM 183, 179 and 68, selected for IAA production (Fig. 5), positively affected the accumulation of $\mathrm{P}$ in the shoot (Fig. 6D). In soybean, LSM 179 and 24 showed the best potential for plant development, corroborating their 
502 in vitro potential, because LSM 179 increased plant height; at the same time, these strains 503 demonstrated new potential, as the N supply increased due to LSM 179, and the dry matter 504 increased due to increased IAA production from LSM 24.

505 In addition to the reported potential of the P. lilacinum strains in this study, it is important 506 to highlight the presence of the M. marquandii strain LSM 68 among those selected for in planta 507 assays. Until 2014, this species was classified as Paecilomyces marquandii, and it is a saprophytic fungus commonly found in soil. Some studies note its potential for application in the bioremediation of heavy metal-contaminated environments, as it is often isolated from this type of environment (Slaba et al., 2011; Slaba et al., 2013), as well as its degradation of alachlor, an herbicide in the chloroacetanilide family (Slaba et al., 2015; Szewczyk et al., 2015). Studies involving M. marquandii are scarce. Ahuja, Ghosh \& D'Souza (2007) and Ahuja \& D'Souza (2009) described the ability of a strain of $M$. (=P.) marquandii to solubilize $\mathrm{P}$ from tricalcium phosphate and Hirapur rock phosphate with starch as the carbon source. Posada et al. (2013) and Ceci et al. (2018) also reported the ability of strains of $M$. $(=P$.) marquandii to solubilize $\mathrm{P}$ from tricalcium and iron phosphate, respectively. Therefore, this study also contributes unpublished information linking M. marquandii to plant growth promotion by testing it under greenhouse conditions and obtaining impressive results regarding P solubilization and transportation in bean plants (Fig. 6D).

The divergence in the in vitro and in planta responses is certainly related to several factors, starting with the tested plant species. The results indicate that each plant species interacts differently with the tested strains, and this arises from aspects such as the location of the fungus, whether it remains in the rhizosphere or interacts endophytically with the plants, whether and how it induces resistance, and whether it produces phytohormones or changes their production in the plant. Thus, in addition to field tests to confirm the potential of these fungi displayed in greenhouse conditions, other tests should be performed in the future to provide a better elucidation of the fungus-plant interaction.

\section{Conclusions}

In addition to several valuable studies that have been published in the context of plant growth promotion combined with the use of microorganisms, this study demonstrates the importance of reporting the unprecedented potential of $P$. lilacinum and $M$. marquandii strains in plants that are agriculturally relevant worldwide and that currently consume millions of tons of agrochemicals and fertilizers in their cultivation. The results herein contribute to the expansion of knowledge that can be used for the development of more sustainable agriculture and confirm that the tested strains can be further explored with the aim of their large-scale application as bioinoculants.

\section{References}

Abbasi MK, Sharif S, Kazmi M, Sultan T, Aslam M. 2011. Isolation of plant growth promoting rhizobacteria from wheat rhizosphere and their effect on improving growth, yield and nutrient uptake of plants. Plant Biosystems 145:159-168.

Ahuja A, D'Souza SF. 2009. Bioprocess for solubilization of rock phosphate on starch based medium by Paecilomyces marquandii immobilized on polyurethane foam. Applied Biochemistry and Biotechnology 152:1-5. 
548 Ahuja A, Ghosh SB, D'Souza SF. 2007. Isolation of a starch utilizing, phosphate solubilizing 549 fungus on buffered medium and its characterization. Bioresource Technology 98:3408-3411. 550 Altschul SF, Gish W, Miller W, Myers EW, Lipman DJ. 1990. Basic Local Alignment Search 551 Tool. Journal of Molecular Biology 215:403-410.

552 Alves SB, Pereira RM. 1998. Producão de fungos entomopatogênicos. In: Alves SB., ed.

553 Controle microbiano de insetos, 2nd edn. Piracicaba, Brazil: Fealq. P. 845-870.

554 Ames, BN. 1966. Assay of inorganic phosphate, total phosphate and phosphatase. Methods in 555 Enzymology 8:115-118.

556 Arzanesh MH, Alikhani HA, Khavazi K, Rahimian HA, Miransari M. 2011. Wheat. (Triticum

557

558

559

560

561

562

563

564

565

566

567

568

569

570

571

572

573

574

575

576

577

578

579

580

581

582

583

584

585

586

587

588

589

590

591 aestivum L.) growth enhancement by Azospirillum sp under drought stress. World Journal of Microbiololy and Biotechnology 27:197-205.

Atkins SD, Clark IM, Pande S, Hirsch PR, Kerry BR. 2005. The use of real-time PCR and species-specific primers for the identification and monitoring of Paecilomyces lilacinus. FEMS Microbiology Ecololy 51:257-264.

Atul-Nayyar A, Hamel C, Hanson K, Germida J. 2009. The arbuscular mycorrhizal symbiosis links N mineralization to plant demand. Mycorrhiza 19:239-246.

Bainier G. 1907. Mycothéque de l'école de Pharmacie. XI. Paecilomyces, genre nouveau de Mucédinées. Bulletin Trimestrielle de la Societe de Mycologie de France 23:26-27. Barbosa JC, Maldonado WJ. 2015. Sistemas para análises estatísticas de ensaios agronômicos (AgroEstat), Jaboticabal: Faculdade de Ciências Agrárias e Veterinárias, Universidade Estadual Paulista.

Bamisile BS, Dash CK, Akutse KS, Keppanan R, Wang LD. 2018. Fungal endophytes: beyond herbivore management. Frontiers in Microbiology 9:544.

Bargaz A, Lyamlouli K, Chtouki M, Zeroual Y, Dhiba D. 2018. soil microbial resources for improving fertilizers efficiency in an integrated plant nutrient management system. Frontiers in Microbiology 9.

Baron NC, Rigobelo EC, Zied DC. 2019. Filamentous fungi in biological control: current status and future perspectives. Chilean Journal of Agricultural Research 79:307-315.

Behie SW, Bidochka MJ. 2014a. Nutrient transfer in plant-fungal symbioses. Trends in Plant Science 19:734-740.

Behie SW, Bidochka MJ. 2014b. Ubiquity of insect-derived nitrogen transfer to plants by endophytic insect-pathogenic fungi: an additional branch of the soil nitrogen cycle. Applied and Environmental Microbiololy 80:1553-1560.

Behie SW, Zelisko PM, Bidochka MJ. 2012. Endophytic insect-parasitic fungi translocate nitrogen directly from insects to plants. Science 336:1576-1577.

Bitterlich M, Rouphael Y, Graefe J, Franken P. 2018. Arbuscular mycorrhizas: a promising component of plant production systems provided favorable conditions for their growth. Frontiers in Plant Science 9:6.

Bills GF; Polishook JD. 1991. Microfungi from Carpinus caroliniana. Canadian Journal of Botany 69(7): 1477-1482.

Bonfante P, Genre A. 2010. Mechanisms underlying beneficial plant-fungus interactions in mycorrhizal symbiosis. Nature Communications 1:11.

Cao LX; You JL; Zhou SN. 2002. Endophytic fungi from Musa acuminata leaves and roots in South China. World Journal of Microbiology and Biotechnology 18(2):169-171. 
592 Cavello IA, Crespo JM, García SS, Zapiola JM, Luna MF, Cavalitto SF. 2015. Plant growth

593 promotion activity of keratinolytic fungi growing on a recalcitrant waste known as "Hair

594 Waste". Biotechnology Research International 2015.

595 Ceci A, Pinzari F, Russo F, Maggi O, Persiani AM. 2018. Saprotrophic soil fungi to improve

596 phosphorus solubilisation and release: In vitro abilities of several species. Ambio 47:30-40.

597 Chen MJ, Zhou N, Li ZZ, Sung GH, Huang B. 2010. Paecilomyces echinosporus sp. nov., a

598 species isolated from soil in China. Mycotaxon 114:2532.

599

600

Coelho AM. 2006. Nutrição e adubação do milho. Embrapa Milho e Sorgo. Circular técnica.

601

Colla G, Rouphael Y, Di Mattia E, El-Nakhel C, Cardarelli M. 2015. Co-inoculation of Glomus

602

intraradices and Trichoderma atroviride acts as a biostimulant to promote growth, yield and

603

nutrient uptake of vegetable crops. Journal of the Science of Food and Agriculture 95:1706-

6041715.

605 CONAB Compania Nacional de Abastecimento. 2016. Compêndio de Estudos Conab: Análise

606 dos custos de produção e retabilidade da cultura do milho 3.

607 CONAB Compania Nacional de Abastecimento. 2017. Compêndio de Estudos Conab: Evolução

608 dos custos da produção de feijão no Brasil e sua rentabilidade 5.

609 CONAB Compania Nacional de Abastecimento. 2019. Acompanhamento da safra brasileira:

610 grãos 6:4.

611 Degenkolb T, Vilcinskas A. 2016. Metabolites from nematophagous fungi and nematicidal

612 natural products from fungi as an alternative for biological control. Part I: metabolites from

613 nematophagous ascomycetes. Applied Microbiology and Biotechnology 100:3799-3812.

614 Dong LQ, Zhang KQ. 2006. Microbial control of plant-parasitic nematodes: a five-party

615 interaction. Plant and Soil 288:31-45.

616 Edgar RC. 2004. MUSCLE: multiple sequence alignment with high accuracy and high

617 throughput. Nucleic Acids Research 32: 792-1797.

618 Ewing B, Hillier L, Wendl MC, Green P. 1998. Base-calling of automated sequencer traces using

619 phred. I. Accuracy assessment. Genome Research 8:175-185.

620 Farias CP, De Carvalho RC, Resende FML, Azevedo LCB. 2018. Consortium of five fungal

621 isolates conditioning root growth and arbuscular mycorrhiza in soybean, corn, and sugarcane.

622 Anais da Academia Brasileira de Ciências 90:3649-3660.

623 Fontaine L, Thiffault N, Pare D, Fortin JA, Piche Y. 2016. Phosphate-solubilizing bacteria

624 isolated from ectomycorrhizal mycelium of Picea glauca are highly efficient at fluorapatite

625 weathering. Botany 94:1183-1193.

626 Gaind S. 2016. Phosphate dissolving fungi: Mechanism and application in alleviation of salt

627 stress in wheat. Microbiological Resesearch 193:94-102.

628 Glass NL, Donaldson GC. 1995. Development of primer sets designed for use with the PCR to

629 amplify conserved genes from filamentous ascomycetes. Applied and Environmental

630 Microbiology 61:1323-1330.

631 Goffré D, Folgarait PJ. 2015. Purpureocillium lilacinum, potential agent for biological control of

632 the leaf-cutting ant Acromyrrnex lundii. Journal of Invertebrate Pathology 130:107-115.

633 Gordon D, Abajian C, Green P. 1998. Consed: A graphical tool for sequence finishing. Genome

634 Research 8:195-202.

635 Green P. 1996. PHRAP documentation. Available online at http://

636 bozeman.mbt.washington.edu/phrap.docs/phrap.html. 
637 Hernandez-Leal TI, Carrión G, Heredia G. 2011. Solubilización in vitro de fosfatos por una cepa 638 de Paecilomyces lilacinus. Thom. Samson. Agrociencia 45:881-892.

639 Hernandez-Leal T, Lopez-Lima D, Carrión G. 2016. Effect of the application of nematophagous 640 fungus Purpureocillium lilacinum over nutrients availability on agricultural soil and yield of 641 Avena sativa. Revista de la Facultad de Ciencias Agrarias 48:1-12.

642 Huson DH, Scornavacca C. 2012. Dendroscope 3: An interactive tool for rooted phylogenetic 643 trees and networks. Systematic Biology 61:1061-1067.

644 Hyde KD, Soytong K. 2008. The fungal endophyte dilemma. Fungal Diversity 33:163-173.

645 Jaroszuk-Ściseł J, Kurek E, Trytek M. 2014. Efficiency of indoleacetic acid, gibberellic acid and

646 ethylene synthesized in vitro by Fusarium culmorum strains with different effects on cereal

647 growth. Biologia 69:281-292.

648 Kepler RM, Humber RA, Bischoff JF, Rehner SA. 2014. Clarification of generic and species

649 boundaries for Metarhizium and related fungi through multigene phylogenetics. Mycologia 650 106:811-829.

651 Kepler RM, Luangsa-ard JJ, Hywel-Jones NL, Quandt CA, Sung GH, Rehner SA, Aime MC, 652 Henkel TW, Sanjuan T, Zare R, Chen MJ, Li ZZ, Rossman AY, Spatafora JW, Shrestha B. 2017. 653 A phylogenetically-based nomenclature for Cordycipitaceae (Hypocreales). Ima Fungus 8:335654353.

655 Khan AL, Hussain J, Al-Harrasi A, Al-Rawahi A, Lee IJ. 2015. Endophytic fungi: resource for 656 gibberellins and crop abiotic stress resistance. Critical Reviews in Biotechnology 35:62-74.

Khan SA, Hamayun M, Yoon H, Kim HY, Suh SJ, Hwang SK, Kim JM, Lee IJ, Choo YS, Yoon UH, Kong WS, Lee BM, Kim JG. 2008. Plant growth promotion and Penicillium citrinum. BMC Microbiology 8:10.

Kuramae-Izioka EE. 1997. A rapid, easy and high yield protocol for total genomic DNA isolation of Colletotrichum gloeosporioides and Fusarium oxysporum. Revista Unimar 19:683689.

663

664

665 Li J, Zou CG, Xu JP, Ji XL, Niu XM, Yang JK, Huang XW, Zhang KQ. 2015. Molecular mechanisms of nematode-nematophagous microbe interactions: basis for biological control of plant-parasitic nematodes. Annual Review of Phytopathology, 53:67-95. Lopez DC, Sword GA. 2015. The endophytic fungal entomopathogens Beauveria bassiana and Purpureocillium lilacinum enhance the growth of cultivated cotton (Gossypium hirsutum) and negatively affect survival of the cotton bollworm (Helicoverpa zea). BioControl 89:53-60. Luangsa-Ard JJ, Hywel-Jones NL, Samson RA. 2004. The polyphyletic nature of Paecilomyces sensu lato based on 18S-generated rDNA phylogeny. Mycologia 96:773-780.

672 Luangsa-ard JJ, Houbraken J, Van Doorn T, Hong SB, Borman AM, Hywel-Jones NL, Samson

673 RA. 2011. Purpureocillium, a new genus for the medically important Paecilomyces

674 lilacinus. FEMS microbiology letters 321 (2):141-149.

Malavolta E, Vitti CV, Oliveira SA. 1997. Avaliação do estado nutricional das plantas: princípios e aplicações 2nd ed, Potafos, Piracicaba, Brasil.

677 Martin JP. 1950. Use of acid, rose bengal, and streptomycin in the plate method for estimating soil fungi. Soil Science 69:215-232.

679 ecosystem comparisons of in situ plant uptake of amino acid-N and NH4 (+). Ecosystems 680 13:177-193.

681 Milani R, Mendes-Santos R, Bentes, LL ; Rigobelo, EC 2019. Bacillus subtilis isolates with 682 different abilities to promote plant growth in maize, cotton, and soybean crops. Asian journal of 
683 microbiology, biotechnology and environmental science 21(4) 5-14.

684 Miransari M. 2011. Arbuscular mycorrhizal fungi and nitrogen uptake. Archives of

685 Microbiology 193:77-81.

686 Miransari M, Bahrami HA, Rejali F, Malakouti MJ. 2009. Effects of soil compaction and

687 arbuscular mycorrhiza on corn (Zea mays L.) nutrient uptake. Soil and Tillage Research

688 103:282-290.

689 Mitchell DJ, Kannwischer-Mitchell ME, Dickson DW. 1987. A semi-selective medium for the 690 isolation of Paecilomyces lilacinus from soil. Journal of Nematology 19:255-256.

691

692

693

694

695

696

697

698

699

700

701

702

703

704

705

706

707

708

709

710

711

712

713

714

715

716

717

718

719

720

721

722

723

724

725

726

727

728

Nahas E, Fornasieri DJ, Assis LC. 1994. Resposta à inoculação de fungo solubilizador de fósforo em milho. Scientia Agricola. 51:463-469.

Nesha R, Siddiqui ZA. 2017. Effects of Paecilomyces lilacinus and Aspergillus niger alone and in combination on the growth, chlorophyll contents and soft rot disease complex of carrot. Scientia Horticulturae 218:258-264.

Nieto-Jacobo MF, Steyaert JM, Salazar-Badillo FB, Nguyen DV, Rostás M, Braithwaite M, Souza JT, Jimenez-Bremont JF, Ohkura M, Stewart A, Mendoza-Mendoza, A. 2017. Environmental growth conditions of Trichoderma spp. affects indole acetic acid derivatives, volatile organic compounds, and plant growth promotion. Frontiers in Plant Science, 8:102. Patil PM, Kuligod VB, Hebsur NS, Patil CR, Kulkarni GN. 2012. Effect of phosphate solubilizing fungi and phosphorus levels on growth, yield and nutrient content in maize (Zea mays). Karnakata Journal of Agricultural Sciences 25.

Perdomo H, Cano J, Gene J, Garcia D, Hernandez M, Guarro J. 2013. Polyphasic analysis of Purpureocillium lilacinum isolates from different origins and proposal of the new species Purpureocillium lavendulum. Mycologia 105:151-161.

Posada D, Buckley TR. 2004. Model selection and model averaging in phylogenetics:

Advantages of akaike information criterion and Bayesian approaches over likelihood ratio tests. Systematic Biology 53:793-808.

Posada D, Crandall KA. 1998. MODELTEST: testing the model of DNA substitution.

Bioinformatics 14:817-818.

Posada RH, Heredia-Abarca G, Sieverding E, de Prager MS. 2013. Solubilization of iron and calcium phosphates by soil fungi isolated from coffee plantations. Archives of Agronomy and Soil Science 59:185-196.

Rai M, Rathod D, Agarkar G, Dar M, Brestic M, Pastore GM, Marostica MR. 2014. Fungal growth promotor endophytes: a pragmatic approach towards sustainable food and agriculture. Symbiosis 62:63-9.

Raij BV, Cantarella H, Quaggio JA, Furlani AMC. 1997. Recomendações de adubação e calagem para o Estado de São Paulo. Campinas: Instituto Agronômico/Fundação IAC. Raij BV, Andrade JC, Cantarella H, Quaggio JA. 2001. Análise química para avaliação da fertilidade de solos tropicais. Campinas: Instituto Agronômico/Fundação IAC.

Ronquist F, Huelsenbeck JP. 2003. MrBayes 3: Bayesian phylogenetic inference under mixed models. Bioinformatics 19:1572-1574.

Shimazu M, Sato H. 1996. Media for selective isolation of an entomogenous fungus, Beauveria bassiana (Deuteromycotina: Hyphomycetes). Applied Entomology and Zoology 31:291-298. Singh S, Pandey RK, Goswami BK. 2013. Bio-control activity of Purpureocillium lilacinum strains in managing root-knot disease of tomato caused by Meloidogyne incognita. Biocontrol Science and Technology 23:1469-1489.

Peer) reviewing PDF | (2019:12:44083:1:2:NEW 13 Mar 2020) 
729

730

731

732

733

734

735

736

737

738

739

740

741

742

743

744

745

746

747

748

749

750

751

752

753

754
Slaba M, Bernat P, Rozalska S, Nykiel J, Dlugonski J. 2013. Comparative study of metal induced phospholipid modifications in the heavy metal tolerant filamentous fungus Paecilomyces marquandii and implications for the fungal membrane integrity. Acta Biochimica Polonica 60:695-700.

Slaba M, Dlugonski J. 2011. Efficient Zn2+ and Pb2+ uptake by filamentous fungus Paecilomyces marquandii with engagement of metal hydrocarbonates precipitation. Internatinal Biodeterioration and Biodegradation 65:954-960. Slaba M, Rozalska S, Bernat P, Szewczyk R, Piatek MA, Dlugonski J. 2015. Efficient alachlor degradation by the filamentous fungus Paecilomyces marquandii with simultaneous oxidative stress reduction. Bioresourse Technology 197:404-409.

Strobel G, Daisy B. 2003. Bioprospecting for microbial endophytes and their natural products. Microbiology and Molecular Biology Reviews 67:491-502.

Sung GH, Hywel-Jones NL, Sung JM, Luangsa-Ard JJ, Shrestha B, Spatafora JW. 2007. Phylogenetic classification of Cordyceps and the clavicipitaceous fungi. Studies in Mycology 57:5-59.

Szewczyk R, Sobon A, Slaba M, Dlugonski J. 2015. Mechanism study of alachlor biodegradation by Paecilomyces marquandii with proteomic and metabolomic methods. Journal of Hazardous Materials 291:52-64.

Tian XL; Cao LX; Tan HM; Zeng QG; Jia YY; Han WQ; Zhou SN. 2004. Study on the communities of endophytic fungi and endophytic actinomycetes from rice and their antipathogenic activities in vitro. World Journal of Microbiology and Biotechnology 20(3): 303309.

White TJ, Bruns T, Lee S, Taylor JW. 1990. Amplification and direct sequencing of fungal ribosomal RNA genes for phylogenetics. In: Innis MA, Gelfand DH, Sninsky JJ, White TJ, eds. PCR protocols: A guide to the methods and applications. New York: Academic Press. p. 315322. 
Figure 1

Bayesian phylogenetic analysis of the ITS region of ribosomal DNA

The sequences of this study are indicated by the LSM code. For the other sequences, the codes preceding the specific name refer to the GenBank accession number (NCBI). The sequences of the P. lilacinum strains CBS 128764, CBS 129077, CBS 346.51 and CBS 119377;

P. lavendulum CBS 128678; and I. farinosa CBS 156.65 were collected from the CBS database. Type $=$ Type strain 


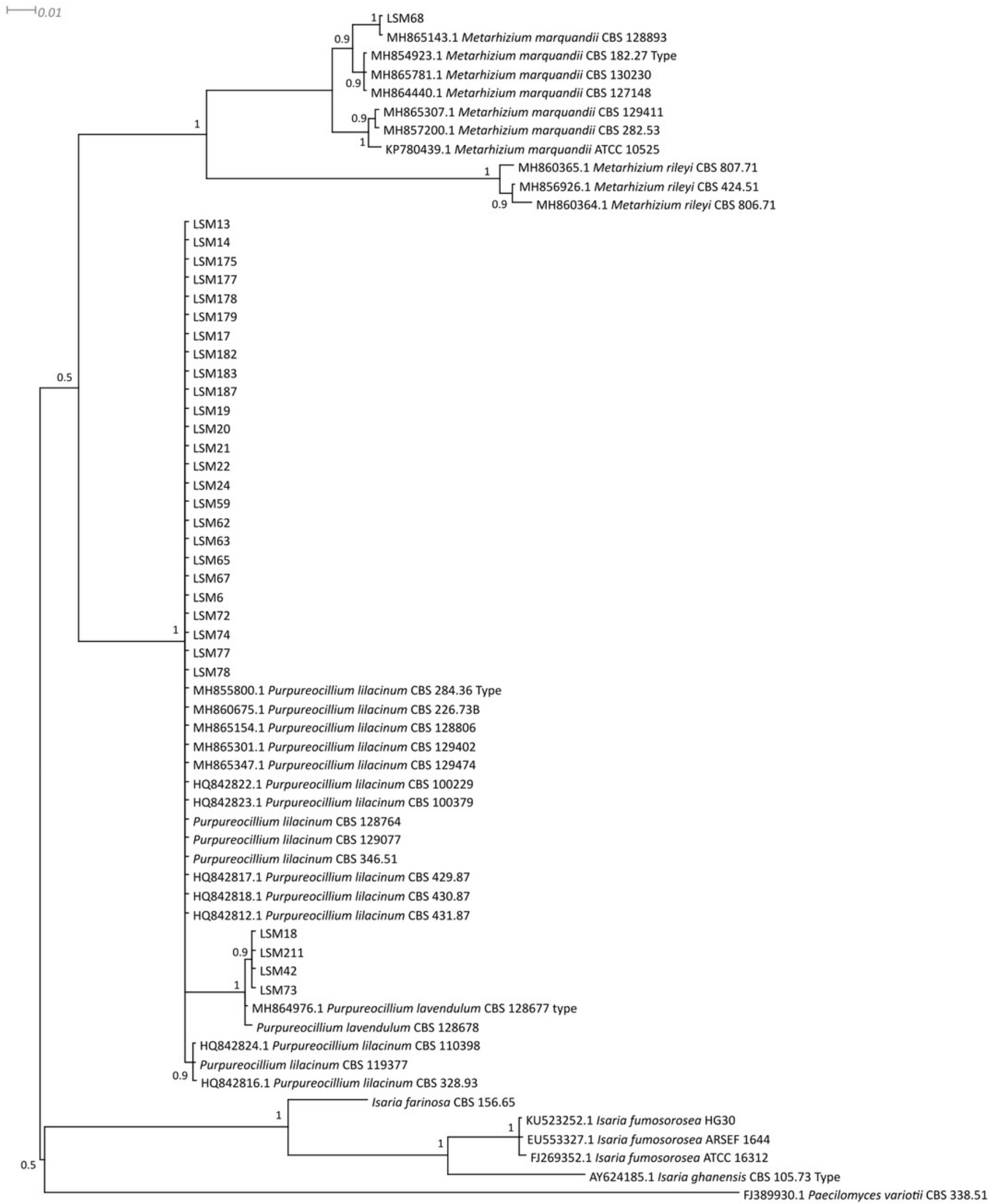


Figure 2

Bayesian phylogenetic analysis of the $\beta$-tubulin coding region

The sequences of this study are indicated by the LSM code. For the other sequences, the codes preceding the specific name refer to the GenBank accession number (NCBI). The sequence for the strain CBS 111113 was collected from the CBS database. Type $=$ Type strain

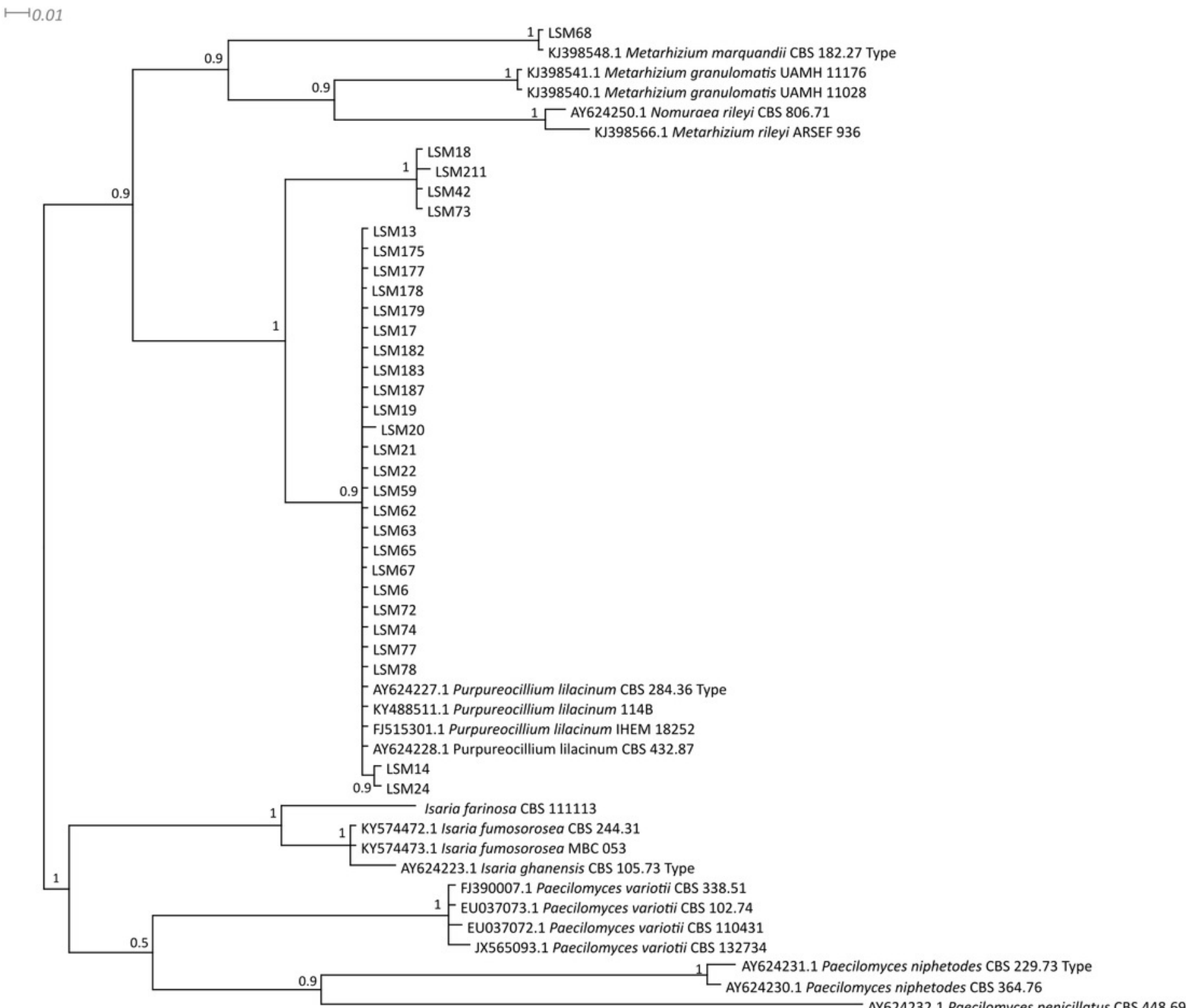


Figure 3

Bayesian phylogenetic analysis of concatenated ITS and $\beta$-tubulin regions sequences

The sequences in this study are indicated by the LSM code. The remaining sequences were collected from the CBS database.

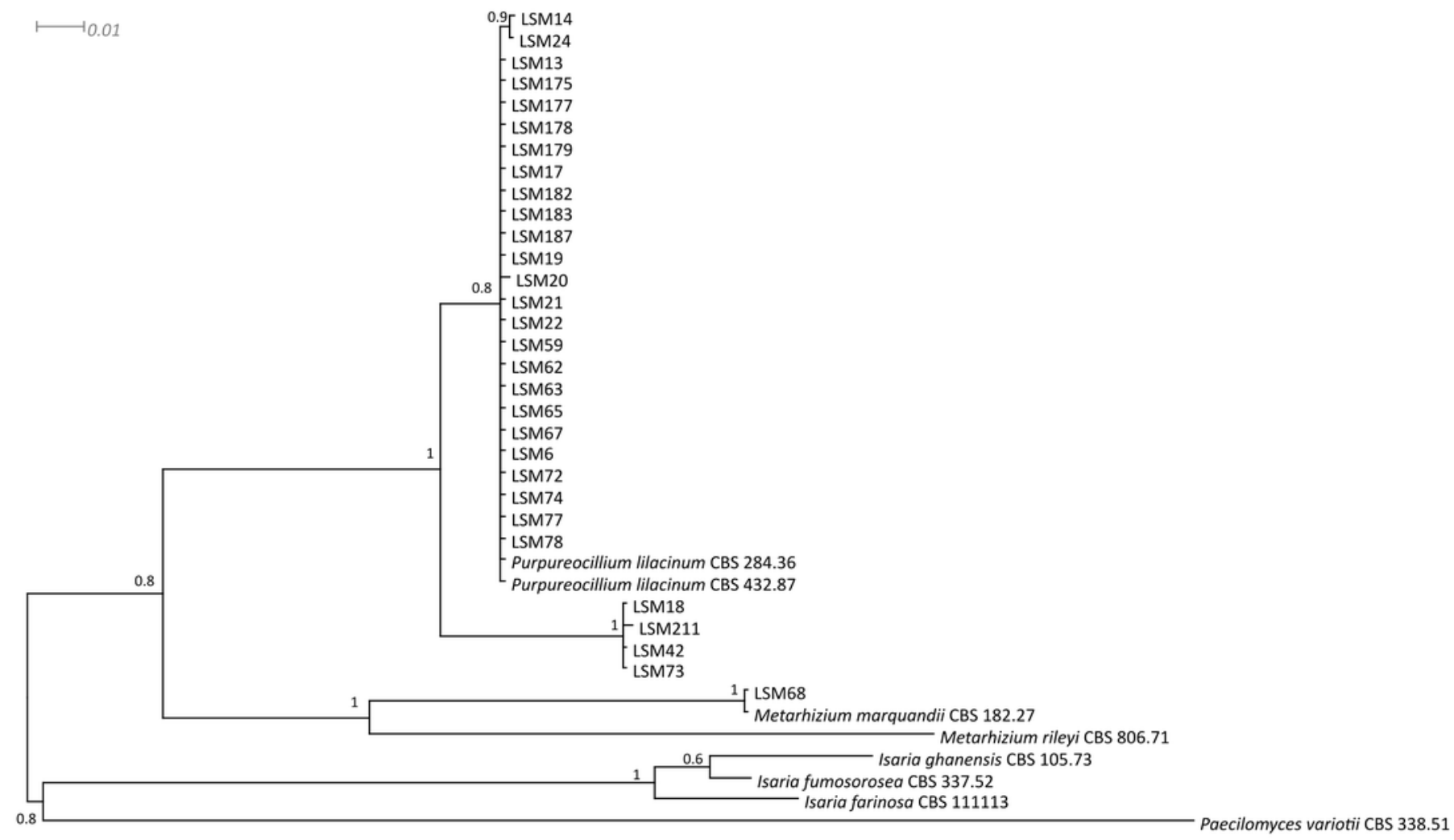




\section{Table $\mathbf{1}$ (on next page)}

In vitro $\mathrm{P}$ solubilization by the 30 fungal strains.

Graphic representation of fluorapatite solubilization by the 30 strains tested. Data are presented as $\mu \mathrm{g}$ of solubilized $\mathrm{P} / \mathrm{g}$ of mycelium produced. The variance analysis ( $\mathrm{F}$ test) was followed by Tukey's test for means comparison at $5 \%$ of probability $(\alpha=0,05)$. Different letters indicate statistical significance. 


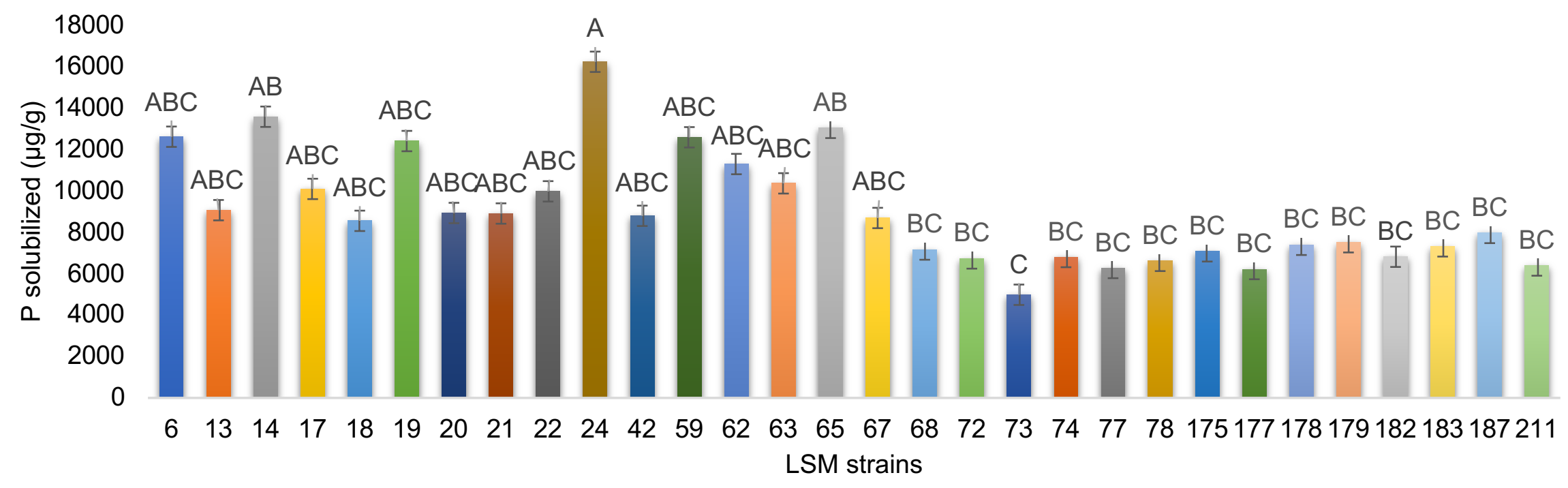




\section{Figure 4}

In vitro IAA production by the 30 fungal strains.

Graphic representation of IAA production by the 30 strains tested. Data are presented as $\mu \mathrm{g}$ of IAA/g of mycelium produced. The variance analysis ( $F$ test) was followed by Tukey's test for means comparison at $5 \%$ of probability $(\alpha=0,05)$. Different letters indicate statistical significance.

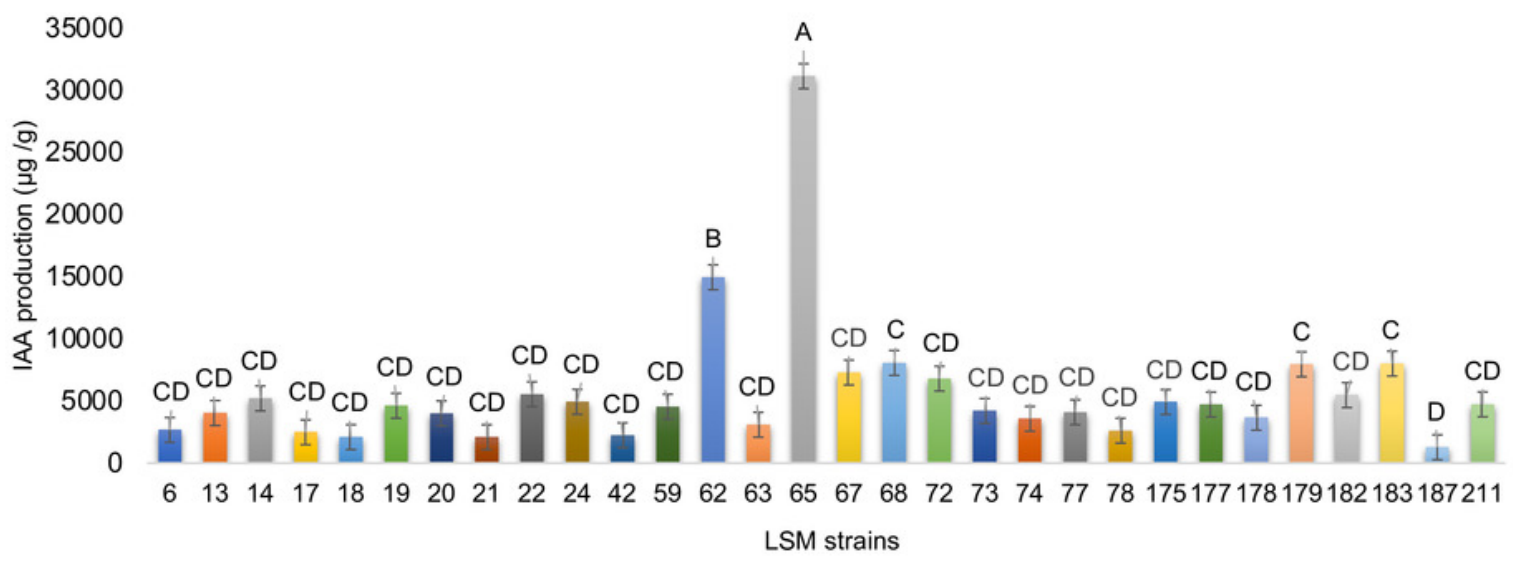


Figure 5

Performance of the selected strains in greenhouse experiment

Graphic ilustration represents the statistical analysis of parameters evaluated. Figures 6A - C depict results of the inoculation of $P$. lilacinum (LSM 14, 24, 62, 65, 179 and 183) and $M$. marquandii (LSM 68) strains on maize. Figure 6D shows the $P$ increase in bean plants shoot and, figures $6 \mathrm{E}-\mathrm{H}$ the effect of fungal inoculation in soybean plants. The variance analysis ( $\mathrm{F}$ test) was followed by Duncan's test for means comparison at $5 \%$ of probability $(\alpha=0,05)$. Different letters indicate statistical significance.

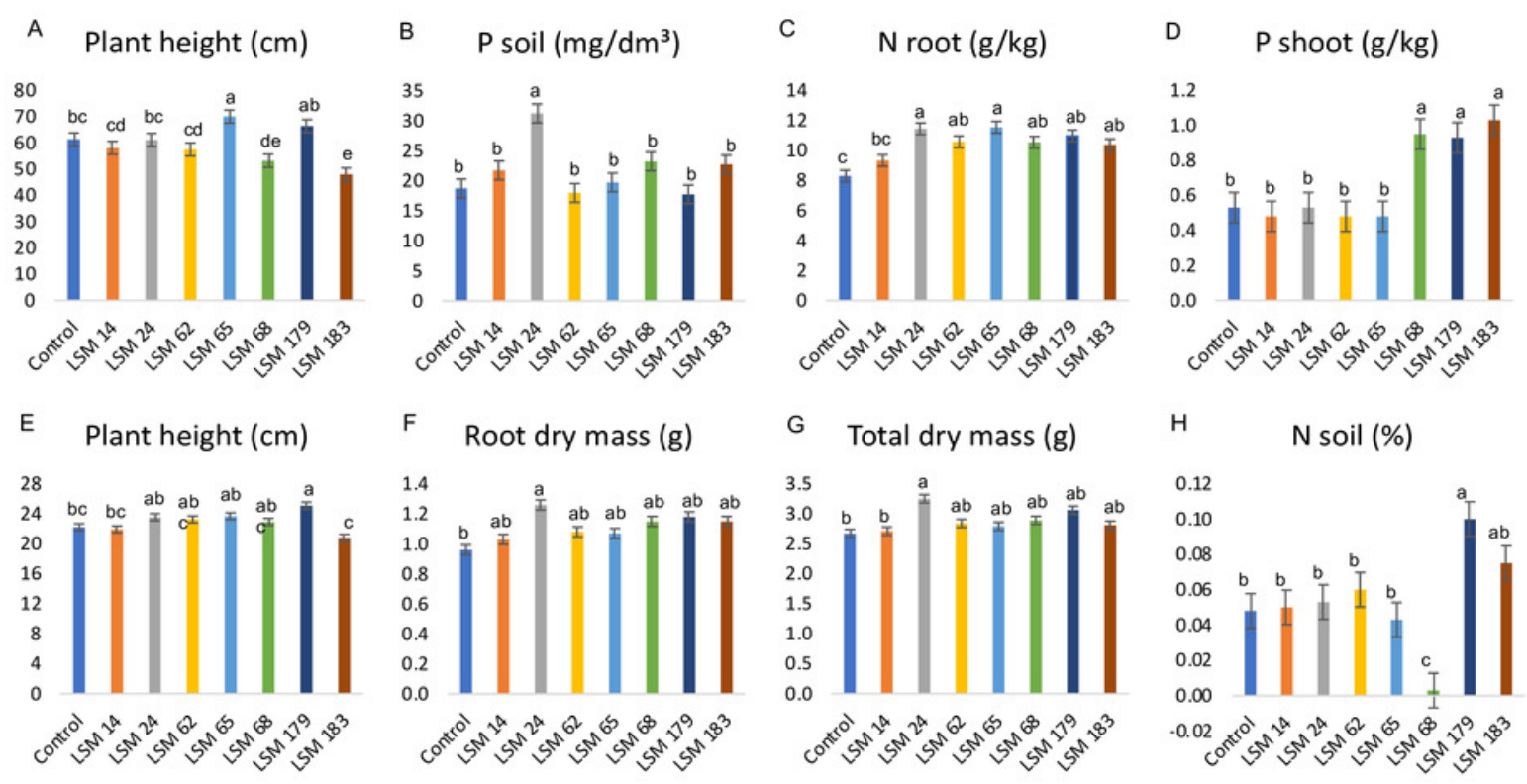




\section{Table 2 (on next page)}

List of all strains used in the phylogenies with their respectives GenBank accession numbers for ITS and $\beta$-tubulin sequences. 
1 Tabel 1:

2 List of all strains used in the phylogenies with their respectives GenBank accession

3 numbers for ITS and $\beta$-tubulin sequences.

\begin{tabular}{|c|c|c|c|}
\hline \multirow{2}{*}{$\begin{array}{c}\text { Cult. Collec. } \\
\text { ID }\end{array}$} & \multirow[t]{2}{*}{ Identification } & \multicolumn{2}{|c|}{ GenBank accession number } \\
\hline & & ITS & $\beta$-tubulin \\
\hline LSM 6 & Purpureocillium lilacinum & MK506343 & MK550664 \\
\hline LSM 13 & Purpureocillium lilacinum & MK506319 & MK550665 \\
\hline LSM 14 & Purpureocillium lilacinum & MK506320 & $\underline{\text { MK550666 }}$ \\
\hline LSM 17 & Purpureocillium lilacinum & MK506325 & MK550667 \\
\hline LSM 18 & Purpureocillium lavendulum & MK506329 & MK550668 \\
\hline LSM 19 & Purpureocillium lilacinum & $\underline{\text { MK506330 }}$ & $\underline{\text { MK550669 }}$ \\
\hline LSM 20 & Purpureocillium lilacinum & $\underline{\text { MK506331 }}$ & $\underline{M K 550670}$ \\
\hline LSM 21 & Purpureocillium lilacinum & $\underline{\text { MK506332 }}$ & $\underline{\text { MK550671 }}$ \\
\hline LSM 22 & Purpureocillium lilacinum & $\underline{\text { MK506334 }}$ & $\underline{\text { MK550672 }}$ \\
\hline LSM 24 & Purpureocillium lilacinum & $\underline{\text { MK506335 }}$ & $\underline{\text { MK550673 }}$ \\
\hline LSM 42 & Purpureocillium lavendulum & $\underline{\text { MK506336 }}$ & $\underline{\text { MK550674 }}$ \\
\hline LSM 59 & Purpureocillium lilacinum & $\underline{\text { MK506337 }}$ & $\underline{\text { MK550675 }}$ \\
\hline LSM 62 & Purpureocillium lilacinum & $\underline{\text { MK506338 }}$ & $\underline{\text { MK550676 }}$ \\
\hline LSM 63 & Purpureocillium lilacinum & $\underline{\text { MK506339 }}$ & $\underline{\text { MK550677 }}$ \\
\hline LSM 65 & Purpureocillium lilacinum & MK506340 & MK550678 \\
\hline LSM 67 & Purpureocillium lilacinum & $\underline{\text { MK506341 }}$ & $\underline{\text { MK550679 }}$ \\
\hline LSM 68 & Metarhizium marquandii & $\underline{\text { MK506342 }}$ & $\underline{\text { MK550680 }}$ \\
\hline LSM 72 & Purpureocillium lilacinum & MK506344 & MK550681 \\
\hline
\end{tabular}




\begin{tabular}{|c|c|c|c|}
\hline LSM 73 & Purpureocillium lavendulum & $\underline{\text { MK506345 }}$ & $\underline{\text { MK550682 }}$ \\
\hline LSM 74 & Purpureocillium lilacinum & $\underline{\text { MK506346 }}$ & MK550683 \\
\hline LSM 77 & Purpureocillium lilacinum & $\underline{\text { MK506347 }}$ & $\underline{\text { MK550684 }}$ \\
\hline LSM 78 & Purpureocillium lilacinum & $\underline{\text { MK506348 }}$ & MK550685 \\
\hline LSM 175 & Purpureocillium lilacinum & MK506321 & $\underline{\mathrm{MK550686}}$ \\
\hline LSM 177 & Purpureocillium lilacinum & $\underline{\text { MK506322 }}$ & $\underline{\text { MK550687 }}$ \\
\hline LSM 178 & Purpureocillium lilacinum & MK506323 & MK550688 \\
\hline LSM 179 & Purpureocillium lilacinum & MK506324 & MK550689 \\
\hline LSM 182 & Purpureocillium lilacinum & MK506326 & $\underline{\text { MK550690 }}$ \\
\hline LSM 183 & Purpureocillium lilacinum & $\underline{\text { MK506327 }}$ & $\underline{\text { MK550691 }}$ \\
\hline LSM 187 & Purpureocillium lilacinum & $\underline{\text { MK506328 }}$ & $\underline{\text { MK550692 }}$ \\
\hline LSM 211 & Purpureocillium lavendulum & $\underline{\text { MK506333 }}$ & $\underline{\text { MK550693 }}$ \\
\hline CBS 284.36 ${ }^{\mathrm{T}}$ & Purpureocillium lilacinum & $\underline{\text { MH855800 }}$ & AY624227 \\
\hline CBS 226.73B & Purpureocillium lilacinum & $\underline{\text { MH860675 }}$ & - \\
\hline CBS 128806 & Purpureocillium lilacinum & $\underline{\text { MH865154 }}$ & - \\
\hline CBS 129402 & Purpureocillium lilacinum & $\underline{\text { MH865301 }}$ & - \\
\hline CBS 129474 & Purpureocillium lilacinum & $\underline{\text { MH865347 }}$ & - \\
\hline CBS 100229 & Purpureocillium lilacinum & HQ842822 & - \\
\hline CBS 100379 & Purpureocillium lilacinum & HQ842823 & - \\
\hline CBS 429.87 & Purpureocillium lilacinum & $\underline{\mathrm{HQ842817}}$ & - \\
\hline CBS 430.87 & Purpureocillium lilacinum & HQ842818 & - \\
\hline CBS 431.87 & Purpureocillium lilacinum & $\underline{\text { HQ842812 }}$ & - \\
\hline CBS 110398 & Purpureocillium lilacinum & HQ842824 & - \\
\hline
\end{tabular}


CBS 328.93 Purpureocillium lilacinum

CBS 128764 Purpureocillium lilacinum

CBS 129077 Purpureocillium lilacinum

CBS 346.51 Purpureocillium lilacinum

CBS 119377 Purpureocillium lilacinum

CBS 432.87 Purpureocillium lilacinum

114 B

IHEM 18252

CBS $128677^{\mathrm{T}}$

CBS 128678 Purpureocillium lavendulum

CBS $128893 \quad$ Metarhizium marquandii

CBS 182.27 ${ }^{\mathrm{T}} \quad$ Metarhizium marquandii

CBS $130230 \quad$ Metarhizium marquandii

CBS 127148 Metarhizium marquandii

CBS 129411 Metarhizium marquandii

CBS 282.53 Metarhizium marquandii

ATCC $10525 \quad$ Metarhizium marquandii

CBS 807.71

CBS 424.51

CBS 806.71

ARSEF 936

UAMH 11176
Purpureocillium lilacinum

Purpureocillium lilacinum

Purpureocillium lavendulum

MH854923

Metarhizium granulomatis
Metarhizium rileyi

Metarhizium rileyi

Metarhizium rileyi

Metarhizium rileyi $\underline{\text { MH864976 }}$

$\underline{\text { MH864977 }}$

$\underline{\text { MH865143 }}$

MH865781

MH864440

$\underline{\text { MH865307 }}$

$\underline{\text { MH857200 }}$

$\underline{\text { KP780439 }}$

$\underline{\text { MH860365 }}$

MH856926

$\underline{\text { MH860364 }}$

AY624228

$\underline{\text { KY488511 }}$

$\underline{\text { FJ515301 }}$

$\underline{\text { KJ388548 }}$

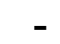

$\underline{A Y 624250}$

$\underline{\text { KJ398566 }}$

$\underline{\text { HM195306 }}$

$\underline{\text { KJ398541 }}$ 


\begin{tabular}{|c|c|c|c|}
\hline UAMH $11028^{T}$ & Metarhizium granulomatis & $\underline{\text { NR } 132013}$ & $\underline{\text { KJ398540 }}$ \\
\hline CBS 156.65 & Isaria $(=$ Cordyceps $)$ farinosa & MH858528 & - \\
\hline CBS 111113 & Isaria $(=$ Cordyceps $)$ farinosa & $\underline{A Y 624181}$ & $\underline{\mathrm{AY} 624219}$ \\
\hline HG 30 & $\begin{array}{c}\text { Isaria }(=\text { Cordyceps }) \\
\text { fumosorosea }\end{array}$ & KU523252 & - \\
\hline ARSEF 1644 & $\begin{array}{l}\text { Isaria }(=\text { Cordyceps }) \\
\text { fumosorosea }\end{array}$ & EU553327 & - \\
\hline ATCC 16312 & $\begin{array}{c}\text { Isaria }(=\text { Cordyceps }) \\
\text { fumosorosea }\end{array}$ & FJ269352 & - \\
\hline CBS 244.31 & $\begin{array}{c}\text { Isaria }(=\text { Cordyceps }) \\
\text { fumosorosea }\end{array}$ & - & $\underline{\text { KY574472 }}$ \\
\hline MBC 053 & $\begin{array}{c}\text { Isaria }(=\text { Cordyceps }) \\
\text { fumosorosea }\end{array}$ & - & $\underline{\text { KY574473 }}$ \\
\hline CBS $105.73^{T}$ & Isaria (=Cordyceps) ghanensis & $\underline{\text { AY624185 }}$ & $\underline{\mathrm{AY} 624223}$ \\
\hline CBS 338.51 & Paecilomyces variotii & $\underline{\text { FJ389930 }}$ & $\underline{\text { FJ390007 }}$ \\
\hline CBS 102.74 & Paecilomyces variotii & - & $\underline{\text { EU037073 }}$ \\
\hline CBS 110431 & Paecilomyces variotii & $\underline{\text { EU037054 }}$ & $\underline{\text { EU037072 }}$ \\
\hline CBS 132734 & Paecilomyces variotii & $\underline{\mathbf{J X 5 6 5 0 8 7}}$ & $\underline{\mathrm{JX565093}}$ \\
\hline CBS $229.73^{\mathrm{T}}$ & Paecilomyces niphetodes & $\underline{\text { NR } 103580}$ & $\underline{A Y 624231}$ \\
\hline CBS 364.76 & Paecilomyces niphetodes & $\underline{\mathrm{AY} 624192}$ & $\underline{A Y 624230}$ \\
\hline CBS 448.69 & Paecilomyces penicillatus & MH859348 & $\underline{A Y 624232}$ \\
\hline
\end{tabular}

\footnotetext{
The table presents the sequences obtained from the strains isolated in this study, identified by the LSM code, and also the sequences collected from NCBI and CBS databases.

$\mathrm{T}$ - Used for sequences of type strain cultures * - Code from CBS database
} 